\title{
Preoperative immunonutrition regulates tumor infiltrative lymphocytes and increases tumor angiogenesis in gastric cancer patients
}

\author{
Kivanc Derya Peker ${ }^{1}$, Sidika Seyma Ozkanli², Cebrail Akyuz ${ }^{1}$, Orhan Uzun ${ }^{1}$, Necdet Fatih Yasar $^{1}$, \\ Mustafa Duman', Sinan Yol ${ }^{3}$
}

\author{
${ }^{1}$ Department of Gastroenterologic Surgery, Kartal Kosuyolu Training and Research \\ Hospital, Istanbul, Turkey \\ 2Department of Pathology, Medical Faculty, Istanbul Medeniyet University, Istanbul, \\ Turkey \\ ${ }^{3}$ Department of General Surgery and Subspecialty (Gastrointestinal) Surgery, Faculty \\ of Health Sciences, Istanbul Medeniyet University, Istanbul, Turkey
}

Submitted: 28 April 2015

Accepted: 6 August 2015

Arch Med Sci 2017; 13, 6: 1365-1372

DOI: 10.5114/aoms.2016.60054

Copyright (C 2016 Termedia \& Banach

\section{Abstract}

Introduction: An increased number of tumor infiltrative lymphocytes (TILs) is considered a favorable prognostic factor in various cancers because it is a marker of antitumoral activity of the immune system. In this prospective, non-randomized clinical trial, we evaluated the impact of preoperative immunonutrition on tumor infiltrative lymphocytes and neoangiogenesis in cancerous tissue in patients with locoregional and resectable gastric adenocarcinoma.

Material and methods: Patients with locoregional and resectable gastric adenocarcinoma were divided non-randomly into two study groups. The first (control) group included patients who had standard nutrition, and the second group included those who had immunonutrition for 7 days before surgery. The biopsy samples taken endoscopically in the preoperative period, as well as the gastrectomy samples, were subjected to immunohistochemical staining for quantitative analysis of CD4, CD8, CD16, CD56, CD31 and CD105 antibodies. Main outcome measures were CD4-to-CD8 ratio and CD105 levels. Results: Fifty patients were included in the study between January 2013 and December 2014. Twenty-five patients were assigned to each of the first and second group. The CD4-to-CD8 ratio and CD105 levels determined in endoscopic biopsy samples were similar in both groups. The CD4-to-CD8 ratio in gastrectomy samples was significantly higher in the first group $(p=0.0001)$. The CD105 levels in gastrectomy samples were significantly lower in the first group $(p=0.01)$.

Conclusions: Seven-day preoperative immunonutrition use regulates TILs in gastric cancer patients, but prolonged use increases tumor angiogenesis.

Key words: immunonutrition, tumor infiltrative lymphocyte, angiogenesis, neovascularization, gastric cancer.

\section{Introduction}

In the inflammatory response key factors including cell division, neovascularization and angiogenesis regulate tumor progression in addition to controlling tumor growth. In the presence of excessive pro-inflamma-

\author{
Corresponding author: \\ Kivanc Derya Peker \\ Denizer Caddesi Cevizli \\ Kavsagi \\ No: 234865 Cevizli \\ Kartal Istanbul, Turkey \\ Phone: +90 5325203656 \\ Fax: +902164596321 \\ E-mail: pekerkivancderya@ \\ gmail.com
}


tory cytokines, neovascularization develops and rapid tumor growth occurs when the balance of pro-inflammatory and anti-inflammatory cytokines is disturbed.

The common consideration in the use of immunonutrition in patients with cancer is to regulate the host's immune response and to control cancer by using the potential immune system present in the host against the tumor to inhibit malnutrition. It is difficult, however, to interpret the observed effects. In this study, we aimed to evaluate the effect of immunonutrition on TILs and neo-angiogenesis.

\section{Material and methods}

The study was designed as a single-center, open label, prospective non-randomized clinical trial. The study was initiated after the approval of the institutional review board. Patients who were diagnosed with gastric tumor between January 2013 and December 2014 were recruited for the study. After the diagnostic work-up and preoperative staging had been completed, patients who were found to have locoregional and resectable gastric adenocarcinoma according to the NCCN Clinical Practice Guidelines in Oncology for Gastric Cancer were included in the study.
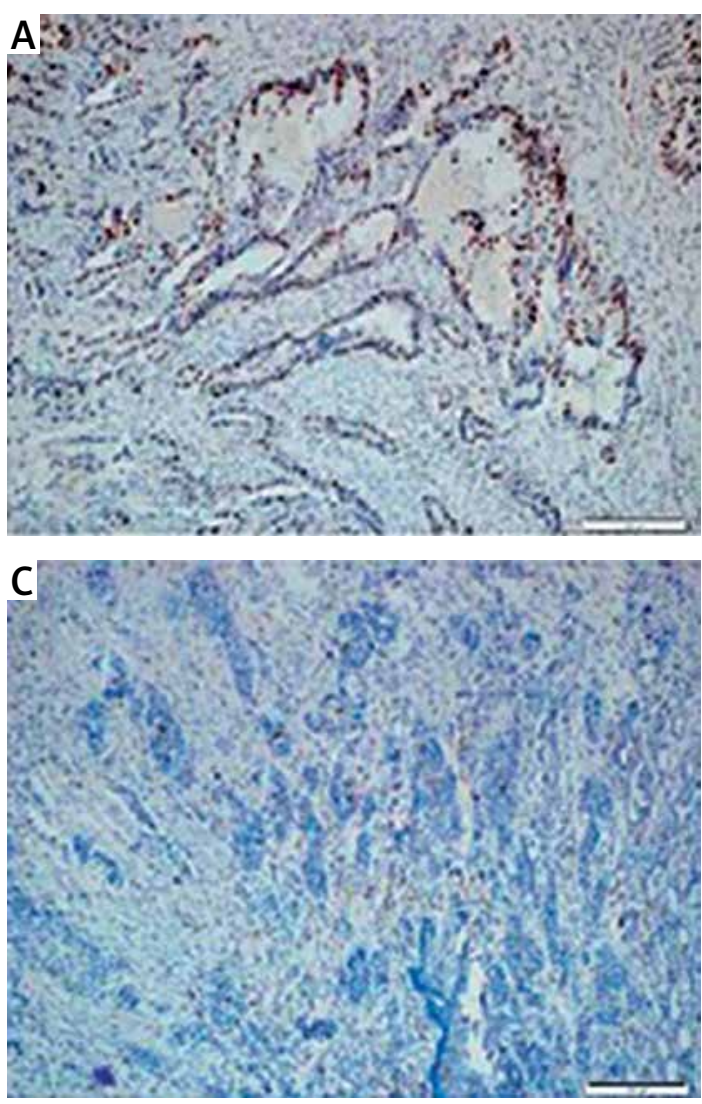

All patients were informed about the study and were requested to sign an informed consent form.

To exclude severe malnutrition, all patients were initially evaluated with anthropometric methods including deviation from ideal body weight, total weight loss within the last 3 months and body mass index.

All patients were hospitalized seven days before surgery. Patients in the first or control group were given a regular diet without any nutritional support, whereas those in the second group had immuno-modulating substrates in addition to the regular diet. For this purpose, patients in the second group were given $237 \mathrm{ml}$ of Impact RTD (Nestle, Istanbul, Turkey) solution, which was given three times a day. Impact RTD (Nestle, Istanbul, Turkey) solution contains arginine, omega-3 fatty acids and nucleotides.

The endoscopic biopsy materials obtained at the initial gastroscopy and the gastrectomy specimens were fixed with formalin, alcohol, xylol and liquid paraffin for $15 \mathrm{~h}$. Afterwards the specimens were embedded in paraffin blocks, which were then sliced into 2-4 micron cross-sections with a microtome (Thermo Finesse ME+). All pathological preparations were subjected to conventional
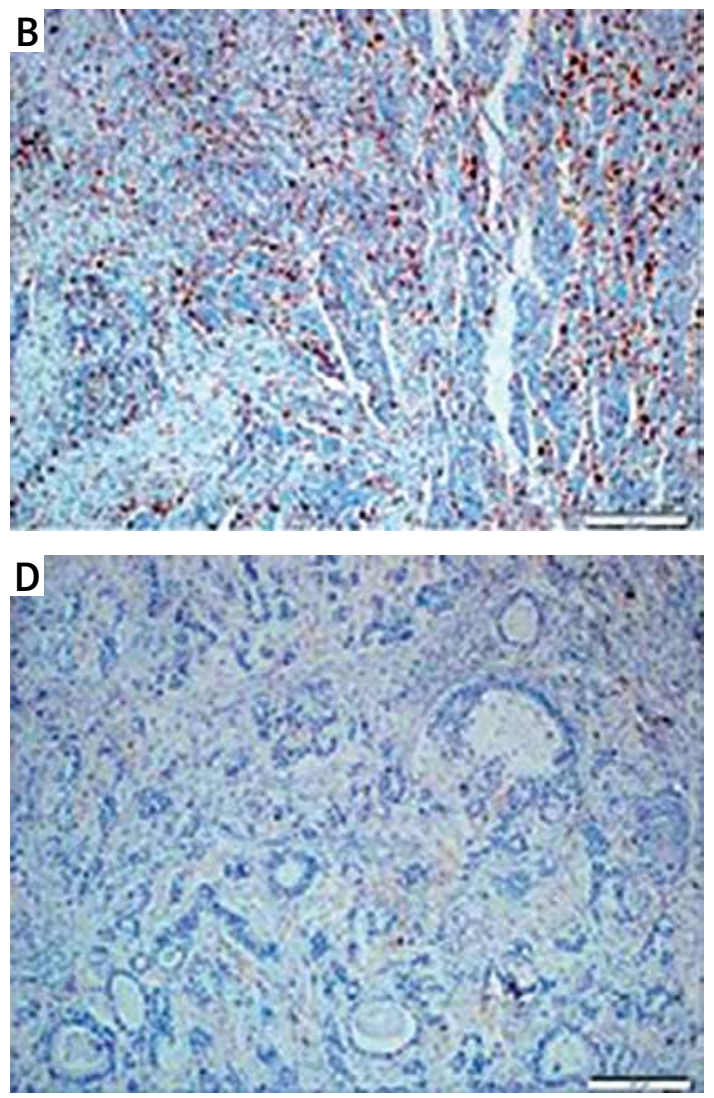

Figure 1. The intraepithelial tumor infiltrative lymphocytes within the tumor are in gastric cancer demonstrated through immunohistochemical staining (brown-stained cells): A - CD4 + stained cells, B - CD8 + stained cells, C - CD16 + stained cells, D - CD56 + stained cells 
staining with hematoxylin-eosin in a fully automated staining device (Leica ST5020, Nussloch, Germany) as well as to immunohistochemical staining with CD4, CD8, CD16, CD56, CD31 and CD105 mouse monoclonal antibody (Novocastra, Leica Biosystems, Newcastle Upon Tyne, United Kingdom) in an immunohistochemical staining device. Product and producer appear to be mudd- led) in four different dilutions $(1 / 20,1 / 20,1 / 80$, $1 / 1,1 / 50$ and $1 / 50$, respectively).

After the procedures were completed, the hematoxylin-eosin-stained preparations were examined for histopathological diagnosis (Figures 1-3).

The immunohistochemically stained samples were examined under a light microscope (Olympus BX-51). The assessment focused on tumor ar-
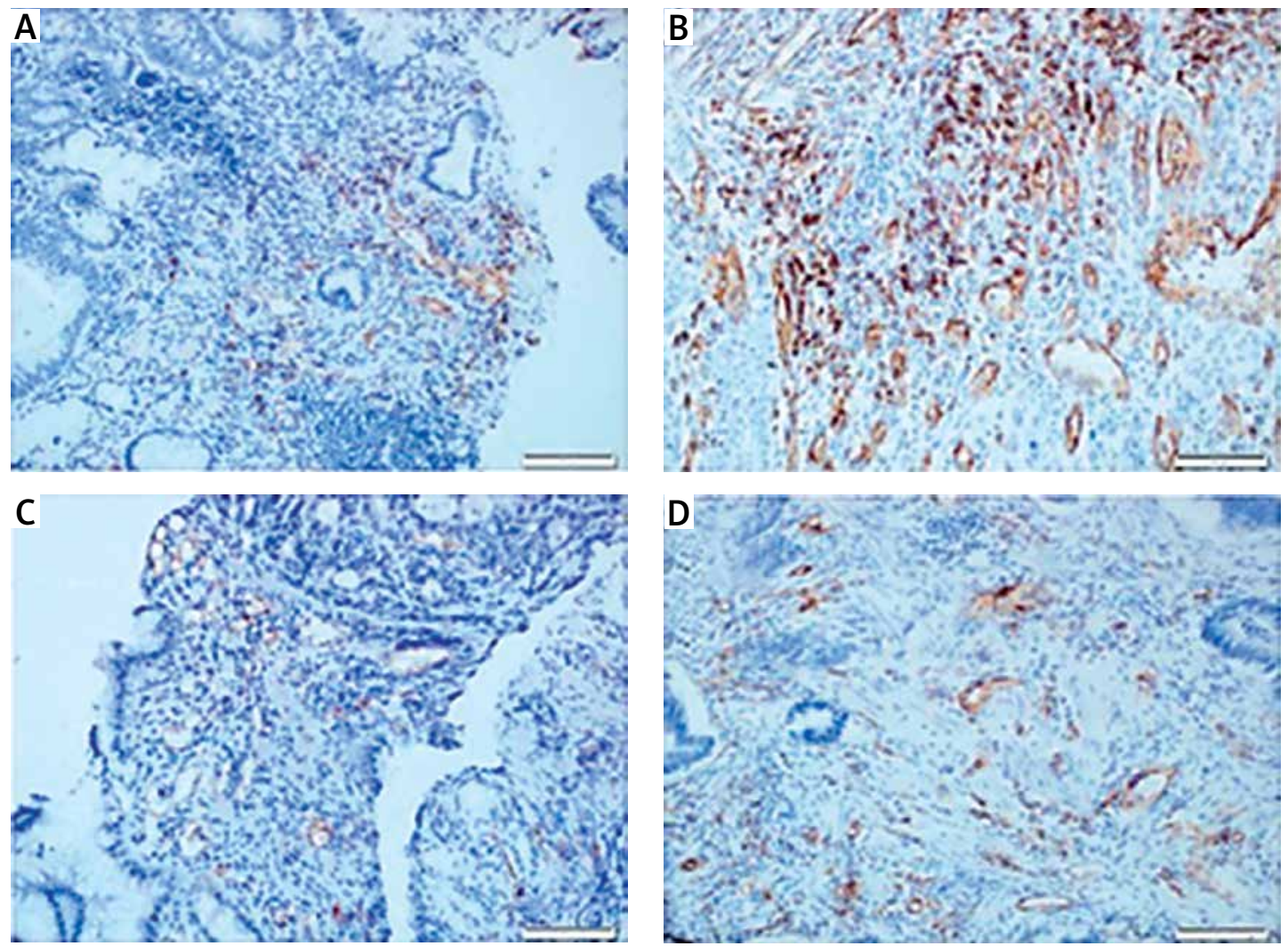

Figure 2. The endothelial cells within the gastric malignant tumor demonstrated immunohistochemical staining with antibodies against CD31 (brown-stained cells) (the most intensely stained samples are presented). Before standard nutrition (A), after standard nutrition (B), before immunonutrition (C), after immunonutrition (D)
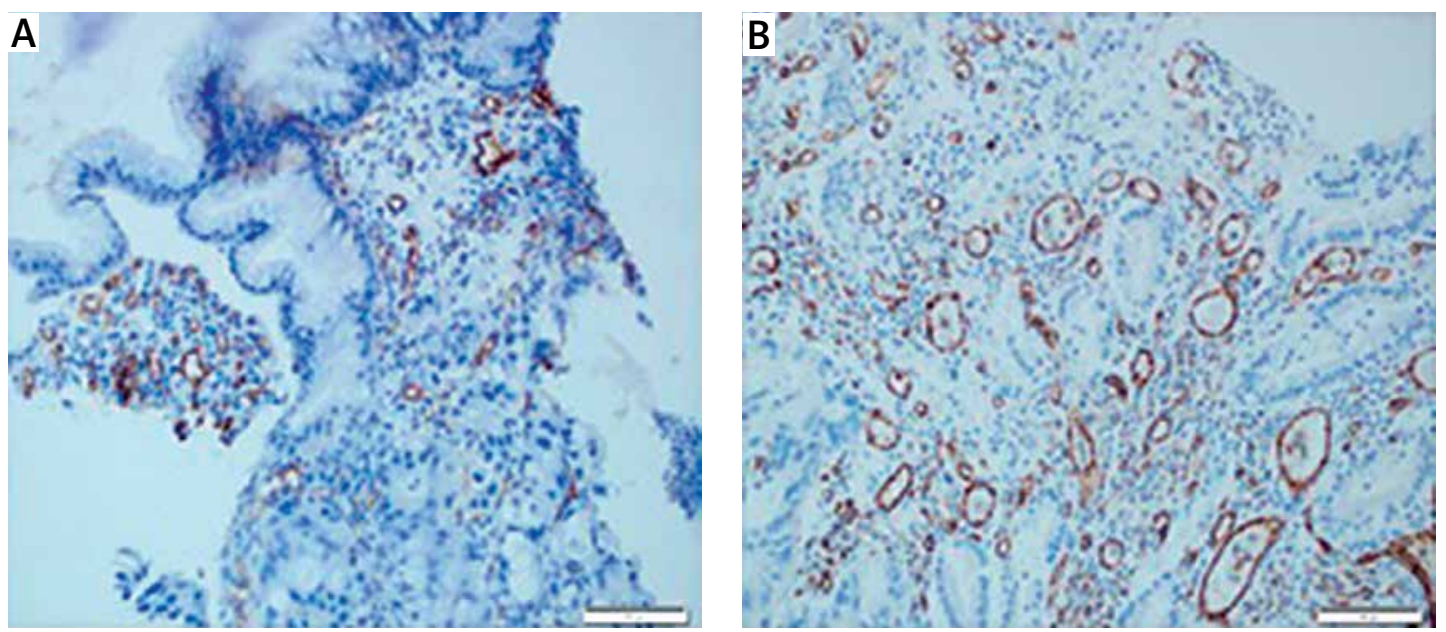

Figure 3. The endothelial cells within the gastric malignant tumor demonstrated immunohistochemical staining with antibodies against CD105 (brown-stained cells) (the most intensely stained samples are presented). After standard nutrition (A), after immunonutrition (B) 
eas and ulcers and ulcer floor areas were excluded from the evaluation. For each immunohistochemically stained tissue, the tumor infiltrating lymphocytes and vessels were counted in 5 different areas under 400× magnification. Only the intraepithelial lymphocytes within the tumor area were accepted as tumor infiltrating lymphocytes. Since immunoreactivity was observed also in the tumor epithelium during the evaluation of CD4, only the cells in lymphocyte morphology were counted.

\section{Statistical analysis}

The statistical analyses were performed using the NCSS (Number Cruncher Statistical System) 2007 Statistical Software (Utah, USA) package. The data were evaluated using definitive statistical methods (mean, standard deviation, median, interquartile range) as well as the independent $t$-test to compare paired groups of variables showing a normal distribution, the Mann-Whitney $U$ test to compare paired groups of variables not showing a normal distribution, and the $\chi^{2}$ test to compare the qualitative data. The results were evaluated at the significance level of $p<0.05$.

\section{Results}

No statistically significant differences were found between the standard nutrition and immunonutrition groups in terms of mean age, gender distribution, surgery type, differentiation distribution, T stage, $\mathrm{N}$ stage or TNM stages (Table I). No statistically significant differences were found between the standard nutrition and immunonutrition groups in terms of the numbers of removed lymph nodes and the numbers of metastatic lymph nodes (Table II). No statistically significant differences were found between the standard nutrition and immunonutrition groups in terms of endoscopic biopsy CD4, CD8, CD16, CD56, CD4/CD8, CD31 and CD105 values (Table III). No statistically significant differences were found between the standard nutrition and immunonutrition groups in terms of CD4, CD8, CD16, CD56 and CD31 values of the surgical pieces $(p>0.05)$.

The CD4/CD8 values of the surgical pieces were significantly higher in the standard nutrition group than in the immunonutrition group ( $p=0.0001)$. The CD105 values of the surgical pieces were significantly lower in the standard nutrition group than in the immunonutrition group $(p=0.01)$ (Table IV).

\section{Discussion}

The guideline on enteral nutrition in surgery published by the European Society for Clinical Nutrition and Metabolism (ESPEN) in 2006 states that pre-operative use of oral nutrition support enhanced with immunomodulating agents reduc-

Table I. Demographics and stage*

\begin{tabular}{|c|c|c|c|c|c|c|}
\hline \multicolumn{2}{|l|}{ Parameter } & \multicolumn{2}{|c|}{ Immunonutrition } & \multicolumn{2}{|c|}{ Standard nutrition } & $P$-value \\
\hline \multicolumn{2}{|l|}{ Age } & \multicolumn{2}{|c|}{$57.92 \pm 10.35$} & \multicolumn{2}{|c|}{$59.12 \pm 13.32$} & 0.846 \\
\hline \multirow[t]{2}{*}{ Gender } & Male & 16 & $64.00 \%$ & 12 & $48.00 \%$ & 0.254 \\
\hline & Female & 9 & $36.00 \%$ & 13 & $52.00 \%$ & \\
\hline \multirow[t]{2}{*}{ Surgery } & Distal & 16 & $64.00 \%$ & 17 & $68.00 \%$ & 0.765 \\
\hline & Total & 9 & $36.00 \%$ & 8 & $32.00 \%$ & \\
\hline \multirow[t]{2}{*}{ Differentiation } & $\mathrm{G} 2$ & 9 & $36.00 \%$ & 8 & $32.00 \%$ & 0.765 \\
\hline & G3 & 16 & $64.00 \%$ & 17 & $68.00 \%$ & \\
\hline \multirow[t]{2}{*}{$\mathrm{T}$} & $\mathrm{T} 2$ & 6 & $24.00 \%$ & 11 & $44.00 \%$ & 0.136 \\
\hline & T3 & 19 & $76.00 \%$ & 14 & $56.00 \%$ & \\
\hline \multirow[t]{4}{*}{$\mathrm{N}$} & NO & 10 & $40.00 \%$ & 10 & $40.00 \%$ & 0.983 \\
\hline & N1 & 6 & $24.00 \%$ & 5 & $20.00 \%$ & \\
\hline & N2 & 6 & $24.00 \%$ & 7 & $28.00 \%$ & \\
\hline & N3a & 3 & $12.00 \%$ & 3 & $12.00 \%$ & \\
\hline \multirow[t]{5}{*}{ Stage } & $1 \mathrm{~B}$ & 3 & $12.00 \%$ & 6 & $24.00 \%$ & 0.503 \\
\hline & $2 \mathrm{~A}$ & 9 & $36.00 \%$ & 5 & $20.00 \%$ & \\
\hline & $2 \mathrm{~B}$ & 5 & $20.00 \%$ & 8 & $32.00 \%$ & \\
\hline & $3 \mathrm{~A}$ & 5 & $20.00 \%$ & 3 & $12.00 \%$ & \\
\hline & $3 B$ & 3 & $12.00 \%$ & 3 & $12.00 \%$ & \\
\hline
\end{tabular}


Table II. Lymph nodes*

\begin{tabular}{|llccc|}
\hline Parameter & & Immunonutrition & Standard nutrition & $P$-value \\
\hline $\begin{array}{l}\text { Number of removed lymph } \\
\text { nodes }\end{array}$ & Mean \pm SD & $24.84 \pm 5.68$ & $24.96 \pm 5.62$ & 0.907 \\
\cline { 2 - 4 } & Median (IQR) & $25(19.5-29.5)$ & $25(19.5-29)$ & \\
\hline $\begin{array}{l}\text { Number of metastatic lymph } \\
\text { nodes }\end{array}$ & Mean \pm SD & $3 \pm 3.71$ & $2.32 \pm 3.41$ & 0.446 \\
\cline { 2 - 4 } & Median (IQR) & $1(0-6)$ & $1(0-4.5)$ & \\
\hline
\end{tabular}

${ }^{\star}$ Mann-Whitney U test.

Table III. Endoscopic biopsy results*

\begin{tabular}{|c|c|c|c|c|}
\hline Variable & & Immunonutrition & Standard nutrition & $P$-value \\
\hline \multirow[t]{2}{*}{ CD4 } & Mean \pm SD & $22.88 \pm 13.46$ & $18.72 \pm 10.66$ & 0.256 \\
\hline & Median (IQR) & $25(10-32.5)$ & $17(10.5-23.5)$ & \\
\hline \multirow[t]{2}{*}{ CD8 } & Mean \pm SD & $17.2 \pm 9.94$ & $15.64 \pm 7.27$ & 0.606 \\
\hline & Median (IQR) & $15(7-25)$ & $15(10-20.5)$ & \\
\hline \multirow[t]{2}{*}{ CD16 } & Mean \pm SD & $1 \pm 3.23$ & $0.84 \pm 1.8$ & 0.238 \\
\hline & Median (IQR) & $0(0-0)$ & $0(0-1)$ & \\
\hline \multirow[t]{2}{*}{ CD56 } & Mean \pm SD & $0.2 \pm 0.71$ & $0.24 \pm 0.52$ & 0.288 \\
\hline & Median (IQR) & $0(0-0)$ & $0(0-0)$ & \\
\hline \multirow[t]{2}{*}{$\mathrm{CD} 4 / \mathrm{CD} 8$} & Mean \pm SD & $1.34 \pm 0.24$ & $1.17 \pm 0.34$ & 0.052 \\
\hline & Median (IQR) & $1.25(1.2-1.6)$ & $1.1(0.95-1.45)$ & \\
\hline \multirow[t]{2}{*}{ CD31 } & Mean \pm SD & $46.24 \pm 36.44$ & $44.96 \pm 17.84$ & 0.431 \\
\hline & Median (IQR) & $40(24.5-53)$ & $45(28-56)$ & \\
\hline \multirow[t]{2}{*}{ CD105 } & Mean \pm SD & $0.64 \pm 0.91$ & $0.6 \pm 1.19$ & 0.472 \\
\hline & Median (IQR) & $0(0-1)$ & $0(0-1)$ & \\
\hline
\end{tabular}

*Mann-Whitney U test.

Table IV. Surgical piece results

\begin{tabular}{|c|c|c|c|c|}
\hline Variable & & Immunonutrition & Standard nutrition & $P$-value \\
\hline \multirow[t]{2}{*}{ CD4 } & Mean \pm SD & $35.8 \pm 21.59$ & $37 \pm 19.2$ & 0.778 \\
\hline & Median (IQR) & $40(12.5-50)$ & $40(20-52.5)$ & \\
\hline \multirow[t]{2}{*}{ CD8 } & Mean \pm SD & $62.8 \pm 36.17$ & $45.4 \pm 26.14$ & 0.064 \\
\hline & Median (IQR) & $60(40-72.5)$ & $45(20-65)$ & \\
\hline \multirow[t]{2}{*}{ CD16 } & Mean \pm SD & $8.4 \pm 20.8$ & $2.2 \pm 4.8$ & 0.181 \\
\hline & Median (IQR) & $0(0-5)$ & $0(0-0)$ & \\
\hline \multirow[t]{2}{*}{ CD56 } & Mean \pm SD & $0.28 \pm 1.06$ & $0.28 \pm 1.02$ & 0.682 \\
\hline & Median (IQR) & $0(0-0)$ & $0(0-0)$ & \\
\hline \multirow[t]{2}{*}{ CD4/CD8 } & Mean \pm SD & $0.56 \pm 0.23$ & $0.84 \pm 0.22$ & 0.0001 \\
\hline & Median (IQR) & $0.6(0.38-0.73)$ & $0.8(0.71-1)$ & \\
\hline \multirow[t]{2}{*}{ CD31 } & Mean \pm SD & $73.44 \pm 40.09$ & $58.04 \pm 30.07$ & 0.101 \\
\hline & Median (IQR) & $66(46.5-85)$ & $47(40.5-76)$ & \\
\hline \multirow[t]{2}{*}{ CD105 } & Mean \pm SD & $10.76 \pm 6.11$ & $6.64 \pm 3.46$ & 0.01 \\
\hline & Median (IQR) & $9(7-15.5)$ & $7(4-8.5)$ & \\
\hline
\end{tabular}

*Mann-Whitney $U$ test. 
es post-operative morbidity and the hospitalization period after major abdominal cancer surgery. Therefore, the guideline recommends pre-operative use for 5-7 days regardless of nutritional risks in patients who will undergo major upper abdominal surgery [1]. On the other hand, nutritional support was only used for the energy need to prevent immune weakness and muscle destruction by supplying essential micronutrition and proteins, but today it is used for modulating immune functions [2-8]. Arginine, omega-3 fatty acids, glutamine, and nucleotides that have positive effects on immune functions have been studied extensively.

Presence of TILS in the tumor microenvironment is an indicator of the immune response of the host, and forms the basis of the cancer immunoediting [9-13]. Presence and increased numbers of lymphocytes are known to be directly associated with survival in many tumors [14]. But the prognostic role of tumor-infiltrating immune cells in patients with gastric cancer is largely unknown. Only a few reports have been issued on the association between tumor infiltrating immune cells and the clinical outcome in gastric cancer. Ishigami et al. [15] reported that patients showing a high level of natural killer cell infiltration in tumor tissues have a better prognosis, and Maehara et al. [16] showed that a high density of dendritic cell infiltration is associated with the absence of lymph node metastasis. On the other hand, the group of Fukuda [17] found no significant difference in survival between patients with marked or slight TIL infiltration. However, they detected TILs by immunostaining in gastric cancer patients, classified cases into groups with marked or slight TIL infiltration, and did not determine TIL numbers.

T-cell-mediated adaptive immunity is considered to play a major role in antitumor immunity. In mouse models, it has been demonstrated that adaptive immunity prevents the development of tumors and inhibits tumor progression [13].

Accordingly, recent data [18] showed that in gastric cancer high densities of immune cells related to adaptive immunity, especially cytotoxic $\mathrm{T}$ cells and memory $\mathrm{T}$ cells, are associated with favorable survival and indicate that adaptive immunity plays a role in the prevention of tumor progression.

The ratio of CD4/CD8 $T$ cells has indeed been used as an indicator for evaluating an individual's immune function. Though some investigations have demonstrated an immunologic antitumor effect of CD4 and CD8 [19], the clinical significance of the $\mathrm{CD} 4 / \mathrm{CD} 8$ ratio in tumor infiltrating lymphocytes and/or in peripheral blood as an indicator of progressive gastrointestinal tumor and/or worse prognosis of patients has been occasionally reported [19]. Diederichsen et al. [20] reported that a low CD4/CD8 ratio in tumor infiltrating lymphocytes is an independent prognostic indicator in patients with colorectal carcinoma. Decrease of the CD4/CD8 ratio is correlated with progressive behavior of the tumor indicated by such tumor-related factors as stage of the tumor, tumor invasion, lymph node metastasis, and size of the tumor in gastric cancer [21].

Another factor associated with survival and metastasis is tumor vascularity. The relationship between tumor vascularity and prognosis of a number of solid tumors is still being investigated. Proteins such as angiogenic cytokines, proteolytic enzymes, and migratory factors are considered to have an effective role in neovascularization. Endoglin (CD105) is one of these factors. It is a member of the transforming growth factor $\beta$ (TGF- $\beta$ ) family, which is active in regulation of cellular activities such as proliferation, migration, production of extracellular matrix and hematopoiesis. Endoglin binds with TGF- $\beta 1$ and TGF- $\beta 3$ receptors with high affinity and induces angiogenesis by antagonizing the inhibitory effect of TGF- $\beta 1$ on endothelial cell [22]. Recent studies have shown that there is a strong association between endoglin and angiogenesis and it is crucial in vascular diseases and tumor progression [23, 24]. Endothelial cells in tumor, inflammatory and regenerative tissues with active angiogenesis exhibit more intense CD105 staining than normal tissues. Additionally, its expression in vessels of preneoplastic lesions is less than in tumor vessels [23]. Pan-endothelial cell markers, such as CD31, CD34 and factor VIII, react with not only newly forming vessels but also normal vessels within tumor tissues. Anti-CD105 antibodies preferentially bind with activated endothelial cells in angiogenic tissues but do not stain or minimally stain endothelial cell in normal tissues. Thus, anti-CD105 antibody is superior to the other endothelial cell markers in evaluation of angiogenesis or angiogenic potential [22-26]. Minhajat et al. investigated organ-specific endoglin in human cancers' angiogenesis and reported that it is specifically expressed in lung, brain, liver, colon, breast and stomach cancers [27]. Wang et al. investigated the expression levels of sinusoidal endothelial cell antibodies (SE-1), CD31 and CD105 in rats with hepatocellular carcinoma and found that there is a strong association between all three markers and angiogenesis [28]. All these findings indicate that CD105 is a specific marker of angiogenesis and is superior to the pan-endothelial cell markers in evaluation of neovascularization. Saad et al. studied the prognostic value of endoglin and vascular endothelial growth factor in esophageal cancers and reported that CD105 is a specific and sensitive prognostic factor for esophageal can- 
cers [29]. Tachezy et al. proposed that the ratio of CD105/CD31 is an index of angiogenesis and is a prognostic factor for intraductal papillary mucinous neoplasm [30]. However, microvascular intensity in cancers, either stained with pan-endothelial marker or CD105, is an indicator of poor prognosis [31-33]. Thus, CD105 and CD31 are used as indicators of neovascularity.

In conclusion, in our study, we found decreased CD4/CD8 ratios in the immunonutrition group compared to the group that received standard nutrition calculated based on the calorie requirement before surgery. This suggests that immunonutrition regulates the balance between Th1 and Th2, and may increase survival based on the other studies on this matter. However, as an interesting result, the CD105 amount was higher in the immunonutrition group than in the standard nutrition group. This led to the conclusion that, based on the studies with endoglin in which immunonutrition was used during the pre-operative period in a manner not compliant with the ESPEN recommendations, this may be associated with metastasis and shorter recurrence rates. These findings can be best interpreted when larger patient series and 5-year survival are investigated.

\section{Conflict of interest}

The authors declare no conflict of interest.

\section{References}

1. Weimann A, Braga M, Harsanyi L, et al. ESPEN Guidelines on Enteral Nutrition: surgery including organ transplantation. Clin Nutr 2006; 25: 224-44.

2. Schneider H, Atkinson SW. Immunonutrition fact or fad. J Nutr Health Aging 2000; 4: 120-3.

3. Ateş E, Yilmaz S, Erkasap S, et al. Perioperative immunonutrition ameliorates the postoperative immune depression in patients with gastrointestinal system cancer (prospective clinical study in 42 patients). Acta Gastroenterol Belg 2004; 67: 250-4.

4. Koretz RL. Immunonutrition. Fact, fantasy, and future. Curr Gastroenterol Rep 2002; 4: 332-7.

5. Evoy D, Lieberman MD, Fahey TJ $3^{\text {rd }}$, Daly JM. The role of arginine. Nutrition 1998; 14: 611-7.

6. Senkal M, Kemen M, Homann HH, Eickhoff U, Baier J, Zumtobel V. Modulation of postoperative immune response by enteral nutrition with a diet enriched with arginine, RNA, and omega-3 fatty acids in patients with upper gastrointestinal cancer. Eur J Surg 1995; 161: 115-22.

7. Clemente CG, Mihm MC Jr, Bufalino R, Zurrida S, Collini P, Cascinelli N. Prognostic value of tumor infiltrating lymphocytes in the vertical growth phase of primary cutaneous melanoma. Cancer 1996; 77: 1303-10.

8. Zheng Y, Li F, Qi B, et al. Application of perioperative immunonutrition for gastrointestinal surgery: a metaanalysis of randomized controlled trials. Asia Pac J Clin Nutr 2007; 16: 253-7.

9. Jass JR. Lymphocytic infiltration and survival in rectal cancer. J Clin Pathol 1986; 39: 585-9.
10. Naito Y, Saito K, Shiiba K, et al. CD8+ T cells infiltrated within cancer cell nests as a prognostic factor in human colorectal cancer. Cancer Res 1998; 58: 3491-4.

11. Schumacher K, Haensch W, Roefzaad C, Schlag PM. Prognostic significance of activated CD8(+) T cell infiltrations within esophageal carcinomas. Cancer Res 2001; 61: 3932-6.

12. Nakano O, Sato $M$, Naito $Y$, et al. Proliferative activity of intratumoral CD8(+) T-lymphocytes as a prognostic factor in human renal cell carcinoma: clinicopathologic demonstration of antitumor immunity. Cancer Res 2001; 61: 5132-6.

13. Dunn GP, Old LJ, Schreiber RD. The immunobiology of cancer immunosurveillance and immunoediting. Immunity 2004; 21: 137-48.

14. Gooden MJ, de Bock GH, Leffers N, Daemen T, Nijman HW. The prognostic influence of tumour-infiltrating lymphocytes in cancer: a systematic review with metaanalysis. Br J Cancer 2011; 105: 93-103.

15. Ishigami S, Natsugoe S, Tokuda K, et al. Prognostic value of intratumoral natural killer cells in gastric carcinoma. Cancer 2000; 88: 577-83.

16. Maehara Y, Tomisaki S, Oda S, et al. Lymph node metastasis and relation to tumor growth potential and local immune response in advanced gastric cancer. Int J Cancer 1997; 74: 224-8.

17. Fukuda K, Tsujitani S, Maeta Y, Yamaguchi K, Ikeguchi M, Kaibara N. The expression of RCAS1 and tumor infiltrating lymphocytes in patients with $\mathrm{T} 3$ gastric carcinoma. Gastric Cancer 2002; 5: 220-7.

18. Lee HE, Chae SW, Lee YJ, et al. Prognostic implications of type and density of tumour-infiltrating lymphocytes in gastric cancer. Br J Cancer 2008; 99: 1704-11.

19. Cho Y, Miyamoto M, Kato K, et al. CD4+ and CD8+ $T$ cells cooperate to improve prognosis of patients with esophageal squamous cell carcinoma. Cancer Res 2003; 63: 1555-9.

20. Diederichsen AC, Hjelmborg JB, Christensen PB, Zeuthen J, Fenger C. Prognostic value of the CD4+/CD8+ ratio of tumour infiltrating lymphocytes in colorectal cancer and HLA-DR expression on tumour cells. Cancer Immunol Immunother 2003; 52: 423-8.

21. Lee WJ, Chang KJ, Lee CS, Chen KM. Selective depression of T-lymphocyte subsets in gastric cancer patients: an implication of immunotherapy. J Surg Oncol 1994; 55 : 165-9.

22. Fonsatti E, Del Vecchio L, Altomonte $M$, et al. Endoglin: an accessory component of the TGFbeta binding receptor complex with diagnostic, prognostic potential in human malignancies. J Cell Physiol 2001; 188: 1-7.

23. Balza E, Castellani P, Zijlstra A, Neri D, Zardi L, Siri A. Lack of specificity of endoglin expression for tumor blood vessels. Int J Cancer 2001; 94: 579-85.

24. Yao Y, Kubota T. Prognostic significance of microvessel density determined by an anti-CD105/endoglin monoclonal antibody in astrocytic tumors: comparison with an anti-CD31 monoclonal antibody. Neuropathology 2005; 25: 201-6.

25. Abdulrauf SI, Edvardsen K, Ho KL, Yang XY, Rock JP, Rosenblum ML. Vascular endothelial growth factor expression and vascular density as prognostic markers of survival in patients with low-grade astrocytoma. J Neurosurg 1998; 88: 513-20.

26. Weidner $\mathrm{N}$. The importance of tumor angiogenesis. The evidence continues to grow. Am J Clin Pathol 2004; 122: 675-7.

27. Minhajat R, Mori D, Yamasaki F, Sugita Y, Satoh T, Tokunaga O. Organ-specific endoglin (CD105) expression in 
the angiogenesis of human cancers. Pathol Int 2006; 56: 717-23.

28. Wang JY, Xu XY, Jia JH, Wu CH, Ge RW. Expressions of SE-1, CD31 and CD105 in the vascular endothelial cells and serum of rat with hepatocellular carcinoma. Chin Med J 2010; 123: 730-3.

29. Saad RS, El-Gohary Y, Memari E, Liu YL, Silverman JF. Endoglin (CD105) and vascular endothelial growth factor as prognostic markers in esophageal adenocarcinoma. Hum Pathol 2005; 36: 955-61.

30. Tachezy M, Reichelt U, Melenberg T, Gebauer F, Izbicki JR, Kaifi JT. Angiogenesis index CD105 (endoglin)/CD31 (PECAM-1) as a predictive factor for invasion and proliferation in intraductal papillary mucinous neoplasm (IPMN) of the pancreas. Histol Histopathol 2010; 25 : 1239-46.

31. Kumar S, Ghellal A, Li C, et al. Breast carcinoma: vascular density determined using CD105 antibody correlates with tumor prognosis. Cancer Res 1999; 59: 856-61.

32. Macchiarini P, Fontanini G, Dulmet E, et al. Angiogenesis: an indicator of metastasis in non-small cell lung cancer invading the thoracic inlet. Ann Thorac Surg 1994; 57: 1534-9.

33. Giatromanolaki A, Koukourakis MI, Comley M, et al. Prognostic value of angiogenesis is a significant prognostic marker in operable non small cell lung cancer. J Pathol 1997; 181: 196-9. 